\title{
Multivariable PID control of an Activated Sludge Wastewater Treatment Process
}

\author{
${ }^{1}$ Norhaliza Abdul Wahab, 2 Reza Katebi and 2Jonas Balderud \\ ${ }^{1}$ Department of Control and Instrumentation Engineering, Faculty of Electrical \\ Engineering, Universiti Teknologi Malaysia, Johor, Malaysia \\ ${ }^{2}$ Industrial Control Centre, Dept of Electronic and Electrical Engineering, \\ University of Strathclyde, Glasgow, UK
}

\section{Introduction}

In general, wastewater treatment plant (WWTP) consists of several stages before it is released to a receiving water body. There are, preliminary and primary treatment (mechanical treatment), a secondary treatment (biological treatment) and a tertiary treatment (chemical treatment). In this chapter, since the work involve of identification and control design of activated sludge process to improve the performance of the system, and most of the control priorities are centred on the biological treatment process, only the secondary treatment will be highlighted.

System modelling and identification of the activated sludge process has provided a wider understanding and a powerful tool to predict the behaviour of the system under different conditions. In control design, system modelling and identification are the most important parts which need be taken into account. Often, models developed for controller design have to be as simple as possible. The simplicity means models can be obtained directly from input-output (or experimental) data and used for control design of WWTP. This type of model is called black box or data-driven model, see for example Box Jenkins (El-Din et al., 2002) and Artificial Neural Network (ANN) proposed by (Cote et al., 1995). It will be shown that the identified data-driven control model describes the activated sludge wastewater system well, at least around an operating point. One of the popular techniques used in the system identification is the subspace identification algorithm and this algorithm is used for the design of control in WWTP. Another approach to modelling is to use model reductions or simplifications. The reduced order (linear) model can be later used for controller design and/or stochastic simulation, see for example (Robertson and Cameron, 1996).

The biochemical processes involved in the activated sludge wastewater treatment process are complex and their understanding was very limited. However, due to the importance of providing concise and efficient information in describing a complicated set of activated sludge system behaviours, several mathematical models have been developed for gaining a better understanding of a real system. In the late $80 \mathrm{~s}$, a more scientific perspective of this biotechnology process was achieved by the first development of International Association for Water Quality (IAWQ) Activated Sludge Model no.1(ASM1) proposed by (Henze et 
al.,1987), followed by a series of mathematical models known as ASM2 and ASM3. Such advanced models of activated sludge processes, i.e. ASM1, have been developed over the years but have not been used for control design due to their high complexity.

As previously mentioned, models developed for controller design have to be as simple as possible. This work attempts to identify simple data-driven control model of activated sludge system. The multivariable identification is performed into a wastewater system using subspace identification technique that provide multivariable model for designing of multivariable PID controller. PID controller is one of the popular conventional methods used from several decades ago. The implementation of this form of feedback controller have been widely used in any industrial processes. Often, this controller is implemented as a local controller, whereby the PID controller is cascaded with the more advanced control method such as model predictive control (MPC). In that case, there are two different control loops in the system that is outer loop (MPC) and inner loop (PID). The outer loop will decide what is the setpoint to be given to the PID control loop. In such cases, the response time of the control variable in the inner loop must be much faster than that given by the outer loop. In any process control such as wastewater treatment plant, scalar PID controller is extensively used to control the process variables of wastewater system. Unfortunately, this type of controller is of no longer sufficient due to the inherently multivariable nature of wastewater system.

For highly multivariable process of wastewater treatment plant, multivariable control systems are therefore needed to handle the inevitable changes in the plant and its effluent characteristics. In literature, several control strategies of interest have been developed to improve effluent quality control of activated sludge wastewater treatment system given by (Chotkowski, W et. al, 2005), (Y. Ma et al., 2005), (Piotrowski, R. Et al., 2005), (A. Stare et al., 2007) and (E. Mats et al., 2006). (A. Stare et al., 2007) for example, reports that the application of advanced control becomes more cost effective despite the need for possible investment in purchasing additional sensors and actuators. This motivate to the use of data-driven control model for the activated sludge process using MPID controller. In multivariable PID control, the control handles more than one input and output in the systems and hence there are usually a number of interacting control loops in the system. This process interaction is of importance issues need to be taken into consideration to ensure better performance of the closed loop plant as well as to meet the current and future demands on effluent water quality. The work of this chapter highlights the effectiveness of using multivariable PID (MPID) control design with the application to activated sludge wastewater treatment process. The design of MPID controller is performed using data driven models developed from system identification techniques based on subspace approach.

\section{Activated sludge wastewater treatment systems}

The activated sludge process is a biological process in which an organic matter is oxidised and mineralised by microorganisms. Oxygen is used by microorganisms to oxidise organic matter. The influent of particulate inert matter and the growth of the microorganisms is removed from the plant as excess sludge to maintain a reasonable suspended solids concentration. A simple activated sludge is usually comprised of an aerator and a settler. The bioreactor includes a secondary clarifier (or settler) that serves to retain the biomass in 
the system while producing a high quality effluent. Part of the settled biomass is recycled to allow the right concentration of microorganisms in the aerated tank. In practice, more than one reactors are commonly applied in the activated sludge process for simultaneous nitrification and denitrification such as one designed in the benchmark COST simulation.

\subsection{Benchmark COST simulation}

A schematic depicting the COST simulation benchmark model is shown in Fig. 1. There are five series biological reactors (or bioreactor) which contain two anoxic and three aerobic tanks and a 10-layer non-reactive secondary settling tank. A pre-denitrifying plant structure has been applied, whereby anoxic process is located at the beginning of the tank, as seen in Fig. 1.

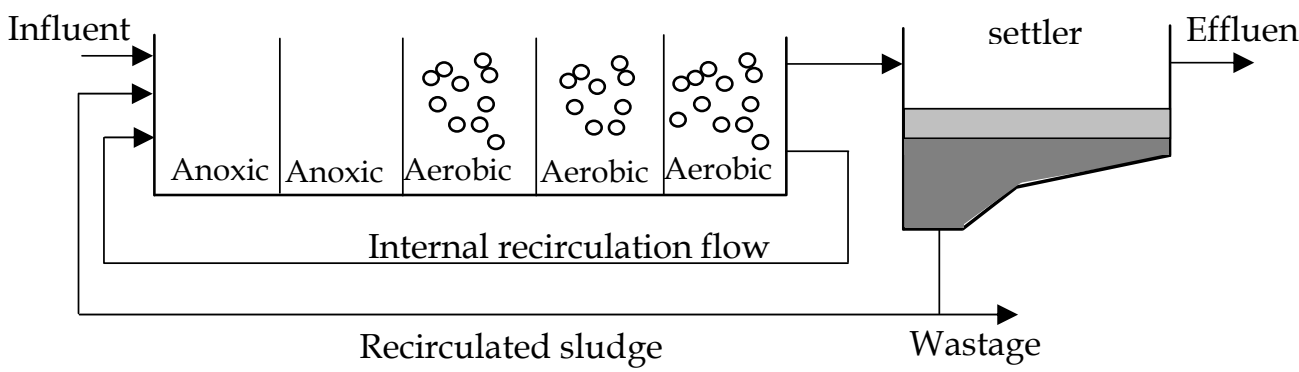

Fig. 1. Activated sludge with pre-denitrification

Each unit of the bioreactor is modelled using IAWQ's ASM1 given by (Henze et al., 1987). The settler is modelled using a double-exponential settling velocity function by (Takács et al., 1991). The bioreactor of ASM1 model describes the removal of organic matter, nitrification and denitrification. To allow for consistent experiment evaluation, the model provides three dynamic data influent flow conditions (or disturbances) and each is meant to be a representative of a different weather condition: dry, rain and storm. For a detailed description of the COST simulation benchmark models, see (Copp, 2002).

\subsection{Control structures of activated sludge with pre-denitrification}

Two different control structures for the activated sludge process are studied. These structures of multivariable control are developed using subspace identification which later used for MPID controller design.

\section{Case 1}

The controller maintains the DO levels in the last three aerobic tanks as seen in Fig. 1, by manipulation of oxygen transfer coefficients $\left(\mathrm{K}_{\mathrm{La}}\right)$. Models are developed at three different operating conditions, i.e. constant influent flow, dry influent flow and rain influent flow conditions. 


\section{Case 2}

In this case, the simultaneous control of DO level $\left(\mathrm{DO}_{5}\right)$ in the last aerobic tank and the control of nitrate $\left(\mathrm{S}_{\mathrm{NO} 2}\right)$ level in the second anoxic tank are considered by manipulation of oxygen transfer coefficient $\left(\mathrm{K}_{\mathrm{La} 5}\right)$ and internal recirculation rate ( $\left.\mathrm{Q}_{\text {intrn }}\right)$. Models are developed for two different operating conditions, i.e. constant influent flow and dry influent flow.

\section{Subspace method of System Identification}

Subspace identification techniques have been (more than 10 years old) developed and have attracted much attention due to their computational simplicity and effectiveness in identifying dynamic state space linear multivariable systems. The subspace identification technique was developed by (De Moor et al., 1988), (Moonen et al., 1989) and (Verhaegen, 1994) and widely known as direct subspace state space system identification (4SID) methods. The advantage of a subspace method is that it is based on reliable numerical algorithms of the QR decomposition and the singular value decomposition (SVD). Moreover, this algorithm can easily be implemented for multi input multi output (MIMO) system identification. The subspace identification uses projection methods and SVD to obtain the model. The identified models in discrete time describe the activated sludge process around an operating point and have been converted to standard continuous linear time invariant state space system:

$$
\begin{aligned}
& \dot{x}(t)=A x(t)+B_{p} u(t)+B_{d} d(t) \\
& y(k)=C x(t)
\end{aligned}
$$

where $x(t)$ is the state vector, $u(t)$ is the input vector, $y(t)$ is the output vector and $\mathrm{d}(t)$ is the measurable disturbance vector. $A, B_{p}, B_{d}$ and $C$ are matrices of appropriate dimensions. Combining the inputs into a single vector gives the following:

$$
\begin{gathered}
\dot{x}=A x(t)+\left(\begin{array}{ll}
B_{p} & B_{d}
\end{array}\right)\left(\begin{array}{l}
u(t) \\
d(t)
\end{array}\right) \\
y(t)=C x(t)
\end{gathered}
$$

The system transfer function is defined as:

$$
G(s)=C(s I-A)^{-1}\left(\begin{array}{ll}
B_{p} & B_{d}
\end{array}\right)
$$

The COST simulation benchmark is used as a data generator for multivariable identification in the activated sludge process. For a better identification result, the data is pre-processed. In this system which is running at steady state operating point different from zero and hence introducing some DC offsets, subtraction of the sample mean from the data set is done in order to remove these offsets. This is common operation in system identification, as 
given by (Söderström and Stoica, 1989). In this work, as the data set is generated from a simulation model, no data filtering is necessary. The data set is finally detrended to remove linear trends from input-output data before it can be later applied to the identification algorithm. The results of model identifications for Case 1 for dry and rain scenarios and for Case 2 for dry influent flow are shown in Fig. 2 (a-c). The sampling time were adjusted to 0.001 days for Case 1 and 0.01 for Case 2. The figure shows only the model responses for aerated tank $4\left(\mathrm{DO}_{4}\right)$.

(a)

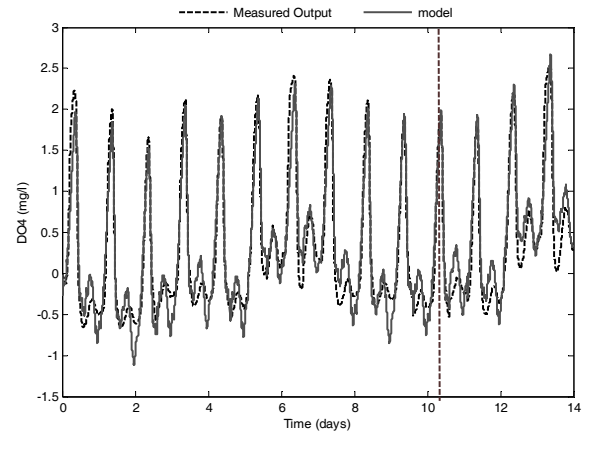

(c)

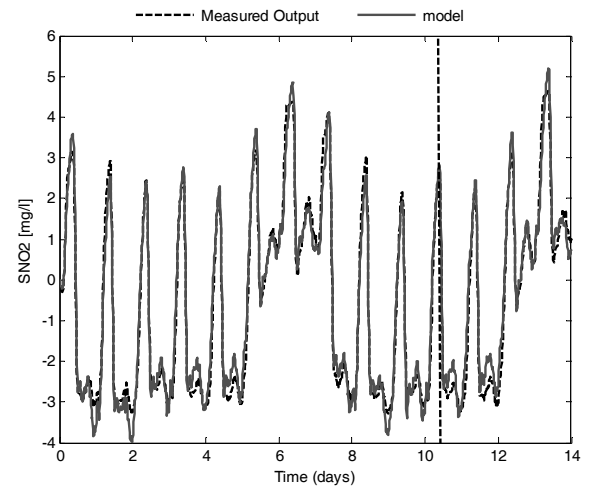

(b)
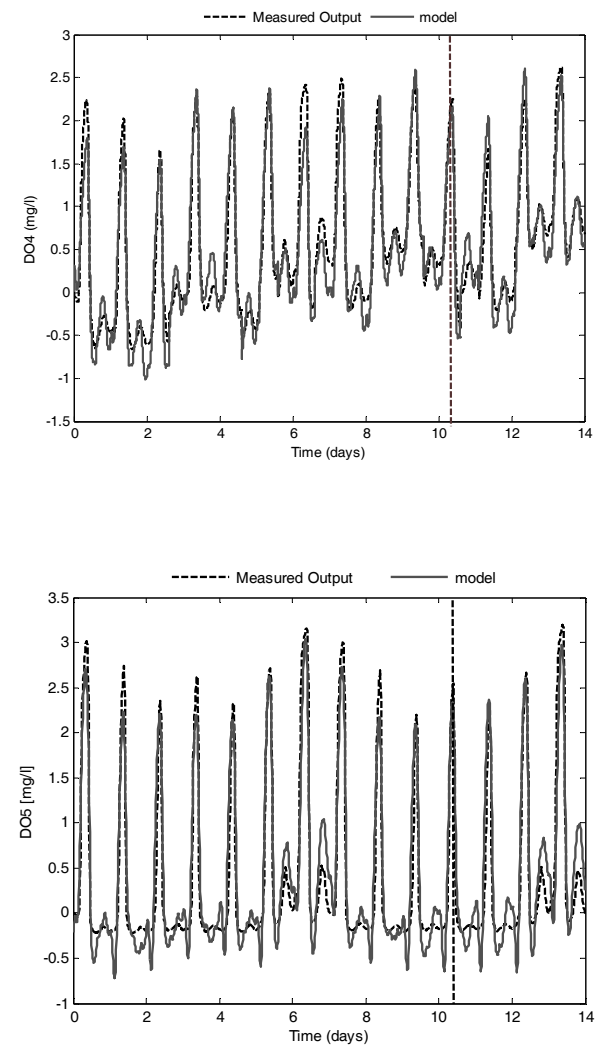

Fig. 2. Response comparison of dynamic influent flows for Cases 1 and 2 - (a) Case 1- dry weather; (b) Case 1- rain weather; (c) Case 2- dry weather

Almost similar results were obtained for the other two outputs $\left(\mathrm{DO}_{3}\right.$ and $\left.\mathrm{DO}_{5}\right)$. In Case 2, the responses are presented for both outputs $\left(\mathrm{S}_{\mathrm{NO} 2}\right.$ and $\left.\mathrm{DO}_{5}\right)$. In dry influent flow, the model identification uses $3 / 4$ of the generated data and the other $1 / 4$ are used for validation. As it can be observed, the identified model for a given operating conditions correctly reproduces the main dynamic characteristics of the activated sludge process. In both cases, the 
simulation started at zero initial conditions. The performance quality of the models are performed by measuring percentage Variance Accounted For (VAF) as follows:

$$
\operatorname{VAF}(\%)=\left(1-\frac{\operatorname{var}(y-\hat{y})}{\operatorname{var}(y)}\right) * 100
$$

where $\mathrm{y}$ and $\hat{y}$ are the measured outputs and predicted outputs, respectively. The bestidentified models are demonstrated by smaller deviations obtained between $y$ and $\hat{y}$ as shown in Tables 1 and 2.

\begin{tabular}{|c|c|c|c|c|}
\hline Model & Order & DO3 & DO4 & DO5 \\
\hline Constant & 6 & 96.65 & 96.05 & 91.4 \\
\hline Dry & 4 & 87.81 & 88.85 & 84.84 \\
\hline Rain & 4 & 87.28 & 89.41 & 82.83 \\
\hline
\end{tabular}

Table 1. Multivariable DO model identification (\%VAF) validation results (Case 1)

\begin{tabular}{|c|c|c|c|}
\hline Model & Order & DO5 & SNO2 \\
\hline Constant & 4 & 92.23 & 97.03 \\
\hline Dry & 4 & 88.42 & 85.63 \\
\hline
\end{tabular}

Table 2. Multivariable DO-Nitrate model identification (\%VAF) validation results (Case 2)

On average, good models were obtained from a given percentage of VAF at around $85 \%$ and above. The identified models obtained were controllable and observable. In both cases, the best responses were obtained for models of order 4 for dynamic influent (i.e. dry and rain) whilst models of order 6 and 4 for constant influent in Case 1 and Case 2, respectively. The poles (eigenvalues of A) shows that both cases the models are open-loop stable. The interaction measure using the Relative Gain Array (RGA) is studied in the following Section.

\subsection{Model analysis}

The interaction analysis is of importance when considering multivariable systems. The RGA analysis should not be interpreted as drawing specific conclusions about the control design but rather it is an indication of how inputs and outputs are interacting and hence the most appropriate control structure can be selected. The most widely used interaction measure for multivariable linear systems so far, is the RGA introduced by (Bristol, 1996).

\subsubsection{Steady state analysis}

The steady state RGA(0) can be calculated as follows:

$$
\begin{gathered}
G(0)=-C A^{-1} B_{p} \\
R G A(0)=\left(-C A^{-1} B_{p}\right) \circ\left(-C A^{-1} B_{p}\right)^{-T}
\end{gathered}
$$


where $G(0)$ is the steady state transfer function matrix and $\circ$ denotes the Schur product (i.e. element-wise multiplication). It can be noted that the calculation for RGA is displayed with three decimal points.

\section{Case 1}

The steady state RGA, $\Lambda(0)$ was calculated for different operating points, i.e. constant, dry and rain influent data sets as follows:

$$
\begin{aligned}
\Lambda^{\text {const }}(0) & =\left[\begin{array}{ccc}
1.042 & -0.017 & -0.024 \\
-0.009 & 1.059 & -0.049 \\
-0.032 & -0.041 & 1.073
\end{array}\right] \\
\Lambda^{d r y}(0) & =\left[\begin{array}{ccc}
1.508 & -0.104 & -0.401 \\
0.560 & 2.076 & -1.640 \\
-1.068 & -0.974 & 3.041
\end{array}\right] \\
\Lambda^{\text {rain }}(0) & =\left[\begin{array}{ccc}
1.588 & -0.052 & -0.540 \\
0.185 & 1.492 & -0.675 \\
-0.777 & -0.439 & 2.217
\end{array}\right]
\end{aligned}
$$

Clearly, most of the off-diagonal elements in the RGA matrix corresponding to the above operating points are negative. For both dry and rain data sets, large values on the diagonal and some negative values on the off-diagonal means that the system is difficult to control using non-interacting control structure since the process exhibit strong and difficult interactions. Here, the RGA matrix represents a system with various extents of interactions: dry influent indicates the strongest interaction within control loops, following by a moderate interaction for rain condition. The lowest interaction is thereby illustrated by constant influent flow.

\section{Case 2}

The analysis of interaction for Case 2 is slightly different from Case 1 so as to allow investigations into the effect of nonlinearities. In this case, the simultaneous controls of nitrate $\left(\mathrm{SNO}_{2}\right)$ level in the second anoxic tank and $\mathrm{DO}\left(\mathrm{DO}_{5}\right)$ level in the last aerobic tank is considered using the manipulation of internal recirculation rate and oxygen transfer coefficient, respectively. Models are developed for two different operating conditions, i.e. constant influent flow and dry influent flow. Under constant influent, three different operating points (refered $\tilde{u}_{1}, \tilde{u}_{2}$ and $\tilde{u}_{3}$ ) are considered to cover a wider range of operating points, i.e. i.e. $\tilde{u}_{1}=\left[\begin{array}{ll}57552 & 88\end{array}\right]^{T} ; \tilde{u}_{2}=\left[\begin{array}{ll}58104 & 210\end{array}\right]^{T}$ and $\tilde{u}_{3}=\left[\begin{array}{ll}83007 & 84.84\end{array}\right]^{T} . \Lambda(0)$ were obtained as follows:

$$
\Lambda_{\tilde{u}_{1}}^{\text {const }}(0)=\left[\begin{array}{cc}
1.031 & -0.031 \\
-0.031 & 1.031
\end{array}\right]
$$




$$
\begin{aligned}
\Lambda_{\tilde{u}_{2}}^{\text {const }}(0) & =\left[\begin{array}{ll}
0.682 & 0.318 \\
0.318 & 0.682
\end{array}\right] \\
\Lambda_{\tilde{u}_{3}}^{\text {const }}(0) & =\left[\begin{array}{ll}
0.948 & 0.052 \\
0.052 & 0.948
\end{array}\right]
\end{aligned}
$$

The off-diagonal elements in the RGA matrix corresponding to the first operating point are negative and the diagonal elements are close to one, the RGA in this case suggests a diagonal controller; that is, $Q_{\text {intrn }}$ should control nitrate concentration and, KLa 5 should be used to control DO concentration. For the second operating point, the diagonal elements are quite far from one and a big value in the off-diagonal elements indicates strong interaction between the control loops. This indicates that a full multivariable control structure is required. The diagonal elements in RGA for the third operating point are also close to one with low interaction in control loops. In the following study, the second operating point will be considered for control design. In addition to that, $\Lambda(0)$ for dry influent flow is as follows:

$$
\Lambda^{d r y}(0)=\left[\begin{array}{cc}
1.558 & -0.558 \\
-0.558 & 1.558
\end{array}\right]
$$

The analysis for the dry influent flow shows almost identical results to constant flow whereby, the anti-diagonal elements in the RGA matrix are negative.

\subsubsection{Dynamic RGA analysis}

Effective control at nonzero frequencies can be studied using the dynamic RGA. Since the controller design methods investigated in this paper require system decoupling at specific frequencies, it is useful to examine dynamic RGA and use the resulting information to decouple the system at frequency points with highest interactions. In the dynamic RGA, the plant gain, $G$ is allowed to be measured at any frequency, $w$. This dynamic version is the extension of the RGA and was proposed by (Kinnaert, 1995) (see reference for a more complete discussion). Not surprisingly, the dynamic version of RGA possesses the same properties as the steady state RGA and is defined as:

$$
R G A(G(i w))=G(i w) \circ\left(G(i w)^{-1}\right)^{-T}
$$

In this case, this RGA version is also denoted by $\Lambda(G)$. It is advisory to study this dynamic RGA which can provide useful information about the behaviour of $\Lambda(G)$ in the interesting frequency range. The $\Lambda(G)$ has been evaluated in both cases of 1 and 2 .

\section{Case 1}

The dynamic study of RGA is evaluated in this case for the three influent flow conditions: constant, dry and rain. Fig. 3 (a-b) shows the behaviour of the real part of $\Lambda(G)$ for dry and rain respectively, over different frequency ranges. 
(a)
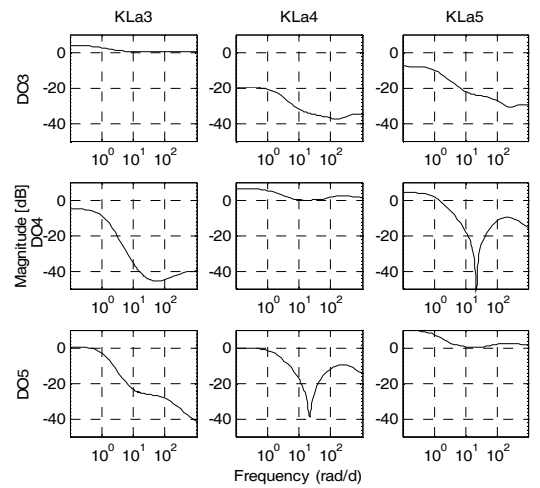

(b)
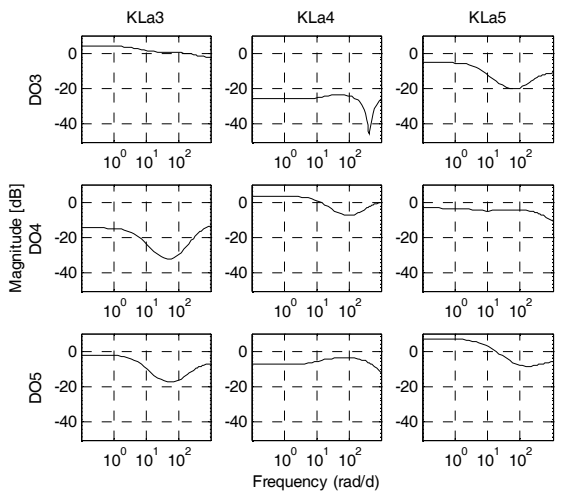

Fig. 3. DRGA gains for dynamic influent flows- a) Case 1- dry weather and b) Case 1 - rain weather

It can be clearly seen that for low and middle frequencies (between $10^{-1} \mathrm{rad} / \mathrm{d}$ and $10^{1} \mathrm{rad} / \mathrm{d}$ ) even higher frequencies the real part is very close to zero for constant influent flow. Hence, the RGA does not suggest a different pairing dynamically than statically. The real part of diagonal elements in both scenarios of dry and rain indicate the process exhibits strong and difficult interactions. For higher frequencies the two dynamic influent conditions (dry and rain) have a real part of $\Lambda(G)$ with a deep valley in some part of the off-diagonals. The curve corresponding to the constant influent flow does not have this property. Overall, dynamic analysis demonstrates that the interactions occur mainly at frequencies about a decade below the open loop bandwidth. Therefore, the low frequency decoupling is most likely to decentralise the control system and minimise the effect of interactions.

\section{Case 2}

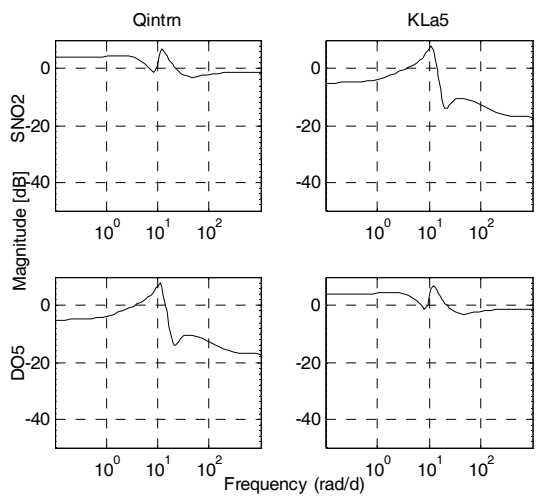

Fig. 4. DRGA gains for dynamic influent flow- a) Case 2- dry weather

The dynamic behaviour of the real part is studied under dry influent flow condition as shown in Fig. 4. Nothing of interest happens for the relevant low and intermediate 
frequency parts for both conditions in this case and it can be conclude that the plots demonstrate the interactions occur mainly at frequencies about a decade below the open loop bandwidth. The low frequency decoupling is therefore most likely to decentralize the control system and to minimise the effect of interactions.

\section{MPID Control Design}

In an attempt to improve the industry acceptance of multivariable control techniques, this study investigates three existing multivariable tuning methods and proposes a new one. These methods require only simple data-driven model of step or frequency response type. Most of the existing controller on WWTPs are not designed or tuned effectively. Hence, a systematic control design method is proposed, which reduces the controller commissioning time as well as the tuning efforts. The methods considered are those suggested in (Davison, 1976), (Penttinen and Koivo, 1980) and (Maciejowski, 1989) and these are compared with a new proposed method.

The design of MPID controllers is best carried out using simple linear models which can be derived from step or frequency tests. These models are usually valid for a single operating point and the procedure should be repeated for other points of interest. Linear models can also be derived by linearising the ASM model around a desired operating point but the resulting model requires to be reduced in size and validated using real data. Hence, the use of data-driven model is preferred. The motivation for using data-driven model is to gain additional insight into the dynamic behaviour of the WWTP and to allow for a more precise determination of the best tuning parameters for each control technique investigated, where the latter will subsequently enable a more objective comparison of the control techniques. Disturbances, in the form of variations of the influent flow rate, $Q_{i n}$, influent ammonium concentration, $S_{\mathrm{NH}}$ and influent substrate $S_{S}$ are considered in this study. The loop interactions are taken into account to determine suitable controller structures for a more effective decoupling.

\subsection{Tuning methods}

This section study tuning of control structures for multivariable systems. For controller tuning, simplicity, as well as optimality, is important. Our intention is to present a framework for multivariable PID controller design which is simple to understand and implement. The control structures and tuning methods investigated in this study are briefly described below.

\subsubsection{Davison method}

The Davison method uses only integral action. The control law is given by:

$$
\underline{u}(s)=K_{i} \frac{1}{s} \underline{e}(s)
$$

where $K_{i}=\varepsilon G^{-1}(0)$ is the integral feedback gain, $G(0)$ is the zero frequency gain of the open loop transfer function matrix, $G(s)$, and $e(s)$ denote the output error. The scalar parameter $\boldsymbol{\varepsilon}$ is the tuning parameter. Since the integral gain is proportional to the inverse of the plant 
dynamics at zero frequency, this method is expected to provide good decoupling characteristics at low frequencies.

\subsubsection{Penttinen - Koivo method}

The Penttinen- Koivo is slightly more advanced than the Davison method. A proportional term has been added to the control law, giving:

$$
\underline{u}(s)=K_{c} \underline{e}(s)+K_{i} \frac{1}{s} \underline{e}(s)
$$

where, $K_{c}=\rho\left(C B_{p}\right)^{-1}$ and $K_{i}=\varepsilon G^{-1}(0)$. The Davison and Penttinen are similar in the sense that the integral gains of both controllers are linearly related to the inverse of the plant dynamics at zero frequency, and both controllers are therefore expected to provide good control-loop decoupling characteristics at low frequencies. Unlike the Davison, the Penttinen controller also includes proportional control action, where the feedback gain is linearly related to the inverse of the plant dynamics at high frequencies. Therefore, by following the same line of reasoning as above, the latter controller is expected to exhibit good decoupling characteristics at high frequencies. The term $C B_{p}$ represents the initial slope of the step output response, i.e.:

$$
C B_{p}=\left[\begin{array}{ccc}
\dot{y}_{1,1} & \cdots & \dot{y}_{1, m} \\
\vdots & \ddots & \vdots \\
\dot{y}_{m, 1} & \cdots & \dot{y}_{m, m}
\end{array}\right]
$$

where $m$ is the system order and $\dot{y}_{i, j}$ is the initial slope of output, $i$, in response to a step at input, $j$. It can be shown that $C G_{p}$ is the inverse of the plant dynamics at high frequencies by writing the Laurent series expansion of the transfer function $\mathrm{G}(\mathrm{s})$ as follows:

$$
G(s)=\frac{C G_{p}}{s}+\frac{C F G_{p}}{s^{2}}+\frac{C F^{2} G_{p}}{s^{3}}+\ldots
$$

A good approximation of $G(s)$ at high frequencies is $G(s)=C B_{p} / s$ is given by (21). As $K_{i} / s$ terms are also negligible at high frequencies compared to $K_{c}$, so it can be concluded that $G(s) K_{c}=I / s$, thus giving the following closed-loop transfer function:

$$
(I+G K)^{-1} G K=\left[\begin{array}{lll}
H_{1}(s) \cdots & 0 \\
\vdots & \ddots & \vdots \\
0 & \cdots & H_{n}(s)
\end{array}\right] \text { for large } s
$$

The tuning parameters, $\rho$ and $\varepsilon$ can be used to tune the proportional and integral gains.

\subsubsection{Maciejowski method}

M3 extends M2 to non-zero frequencies and hence the controller gains are linearly related to the inverse of the plant dynamics at a particular design frequency, $w_{b}$, i.e. 
$K_{c}=\rho G^{-1}\left(j w_{b}\right)$, and $K_{i}=\varepsilon G^{-1}\left(j w_{b}\right)$. The calculation $G^{-1}\left(j w_{b}\right)$ will typically lead to a complex matrix, and hence a real approximation of $G^{-1}\left(j w_{b}\right)$ is required. This can be achieved by solving the following optimisation problem:

$$
\begin{aligned}
& J(K, \Theta)=\left[G\left(j w_{b}\right) K-e^{j \Theta}\right]^{T}\left[G\left(j w_{b}\right) K-e^{j \Theta}\right], \\
& \Theta=\operatorname{diag}(\theta 1, \ldots, \theta n)
\end{aligned}
$$

By appropriately selecting the matrix $K$ to minimise $J$ the product of $G\left(j w_{b}\right)$ and $K$ will be close to the identity matrix at the design frequency, and therefore this will provide good control-loop decoupling characteristics around this frequency. This method suffers from a non-trivial frequency analysis.

\subsubsection{A proposed new method}

Before entering the method description, a short remark on the relevance of the problem is presented. Nowadays many wastewater treatment plants use very simple control technologies such as PID control. To this point, the study presented herein is then an attempt to give a quantitative basis, as rigorously as possible, to a practice that is widely adopted in industrial process. The initial benchmark result indicates that a multivariable PID controller was very effective for the control problem posed by the WWTP benchmark problem. The studied control design strategies presented a reasonable performance of system. Since the main characteristic of the proposed approach is to improve control performance while retaining the simplicity of the multiloop strategy, it will involve enhancements to the PID control calculations; such that, we try to combine some specification of different existing methods to obtain both a good performance of control as well as disturbance rejection, also to minimise the interaction. To devise the proposed method, some quantities useful to characterise an existing tuning method is discussed. The Davison is of no use where integrators are present in the process. Penttinen-Koivo requires the system that have a high frequency motion. The design technique proposed by Maciejowski approximates decoupling at a selected frequency. It has many tractable properties and an intuitive control structure. Initial results also indicated that the controller was effective only for the control problem where all the loops have similar bandwidth frequencies and it also requires a rigorous frequency analysis. This work therefore proposes a new control design technique that retains some of the properties that makes the Maciejowski controller tractable, but eliminates the need for frequency analysis and it is more effective for systems which have control loops of different bandwidths. The proposed control design technique assumes the following control structure:

$$
\underline{u}(s)=\underline{e}(s)\left(\rho K+\varepsilon K \frac{1}{s}\right)
$$

where,

$$
K=\left[\alpha G(0)+(1-\alpha) C G_{p}\right]^{-1}
$$


The proportional and integral feedback gain of the proposed controller is a blend between the inverse of the plant dynamics at zero frequency and the inverse of the plant dynamics at high frequency. Thus, provided the plant have low-pass frequency characteristics, a good approximation of $G^{-1}\left(j w_{b}\right)$ can be obtained by appropriately selecting the additional controller tuning parameter, $\alpha \in\left[\begin{array}{ll}0 & 1\end{array}\right]$.

\subsection{Optimal tuning of MPID controller}

To allow for an objective comparison of the performance achieved by the MPID controllers, the tuning parameters for each controller has been adjusted such that the following penalty function, $J$ is minimised:

$$
J=\int_{0}^{\infty} \tilde{x}(t)^{T} Q \tilde{x}(t)+u(t)^{T} R u(t)
$$

where (26) minimises the energy corresponds in some sense to keep the state and the control close to zero. $\tilde{x}(k)=\left[\begin{array}{ll}x(k) & v(k)\end{array}\right]^{T}$ denotes the controller integrator states. The weighting matrices, $Q$ and $R$, are non-negative definite symmetric matrices; tuned in such a way that a satisfactory closed loop performance is obtained. In this case, we obtain $Q=\operatorname{diag}\left(10^{6}, 10^{6}\right.$, $10^{6}$ ) and $R=0.001 I$ that produces good performance. It was assumed that the process dynamics and controller states could be described using:

$$
\begin{gathered}
\dot{\tilde{x}}(t)=A \tilde{x}(t)+B u(t) \\
y(t)=C \tilde{x}(t)
\end{gathered}
$$

Under these assumptions the MPID control laws could be expressed as:

$$
\begin{gathered}
u(t)=-K \tilde{x}(t) \\
\dot{u}(t)=-K \dot{\tilde{x}}(t)=-K(A \tilde{x}(t)+B u(t))
\end{gathered}
$$

where $K=\left[K_{c} K_{i}\right]$. The penalty function may be expressed in terms of $K$ as:

$$
J=\int_{0}^{\infty} \tilde{x}(t)^{T}\left(Q+K^{T} R K\right) \tilde{x}(t)=\tilde{x}(t)^{T} P \tilde{x}(t)
$$

By assuming that the closed loop system is asymtotically stable so that $J$ becomes:

$$
J=x(0)^{T} P x(0)
$$

where $P$ denotes the solution to the following steady state Lyapunov equation:

$$
A_{c}^{T} P+P A_{c}+Q+K^{T} R K=0
$$


where $A_{c}=A-B K$. Thus, for each MPID control scheme, the controller parameters, $\varphi$ is selected such that the matrix norm of $P$ is minimised, i.e.:

$$
\min _{\varphi}\|P\|,
$$

where $\varphi$ is given in Table 3 and Table 4 for both Cases 1 and 2, respectively.

\begin{tabular}{|c|c|c|c|}
\hline & Constant & Dry & Rain \\
\hline M1 & $\begin{aligned} K_{i} & =\left[\begin{array}{ccc}68.11 & 0.238 & -6.30 \\
-18.7 & 64.95 & -16.63 \\
-5.09 & -11.7 & 62.33\end{array}\right] \\
\varepsilon & =126\end{aligned}$ & $\begin{aligned} K_{i} & =\left[\begin{array}{ccc}59.14 & 26.06 & -40.77 \\
-37.30 & 124.33 & -65.83 \\
-9.23 & -23.39 & 28.20\end{array}\right] \\
\varepsilon & =195\end{aligned}$ & $\begin{aligned} K_{i} & =\left[\begin{array}{ccc}75.294 & 13.37 & -41.365 \\
-18.162 & 80.695 & -39.243 \\
-20.946 & -19.925 & 38.292\end{array}\right. \\
\varepsilon & =239\end{aligned}$ \\
\hline M2 & $\begin{aligned} K_{c} & =\left[\begin{array}{ccc}0.164 & 0.004 & 0.01 \\
0.0 & 0.183 & 0.003 \\
0.003 & 0.002 & 0.144\end{array}\right] \\
K_{i} & =\left[\begin{array}{ccc}68.11 & 0.238 & -6.30 \\
-18.7 & 64.95 & -16.63 \\
-5.09 & -11.7 & 62.33\end{array}\right] \\
\rho & =283 \quad \varepsilon=545\end{aligned}$ & $\begin{aligned} K_{c} & =\left[\begin{array}{ccc}0.201 & -0.04 & -0.02 \\
0.009 & 0.127 & -0.232 \\
-0.019 & -0.014 & 0.297\end{array}\right] \\
K_{i} & =\left[\begin{array}{ccc}59.14 & 26.06 & -40.77 \\
-37.30 & 124.33 & -65.83 \\
-9.23 & -23.39 & 28.20\end{array}\right] \\
\rho & =166 \quad \varepsilon=510\end{aligned}$ & $\begin{aligned} K_{c} & =\left[\begin{array}{ccc}0.159 & -0.088 & 0.185 \\
-0.063 & 0.113 & 0.002 \\
-0.041 & -0.043 & 0.131\end{array}\right] \\
K_{i} & =\left[\begin{array}{ccc}75.294 & 13.37 & -41.365 \\
-18.162 & 80.695 & -39.243 \\
-20.946 & -19.925 & 38.292\end{array}\right] \\
\rho & =500 \varepsilon=784\end{aligned}$ \\
\hline M3 & $\begin{array}{l}K=\left[\begin{array}{ccc}0.013 & -0.0 & -0.001 \\
0.001 & 0.013 & -0.0 \\
0.0 & 0.001 & 0.011\end{array}\right] \\
\rho=4800 \varepsilon=2581800 \omega=53\end{array}$ & $\begin{aligned} K & =\left[\begin{array}{ccc}0.014 & 0.0 & 0.0 \\
0.003 & 0.015 & 0.002 \\
0.001 & 0.002 & 0.014\end{array}\right] \\
\rho & =4000 \varepsilon=1326700 \omega=50\end{aligned}$ & $\begin{array}{l}K=\left[\begin{array}{ccc}0.013 & 0.002 & 0.004 \\
-0.001 & 0.016 & -0.0 \\
0.003 & 0.011 & 0.031\end{array}\right] \\
\rho=9300 \varepsilon=1733700 \omega=100\end{array}$ \\
\hline M4 & $\begin{array}{c}K=\left[\begin{array}{ccc}37.029 & 0.165 & -0.860 \\
-6.271 & 37.464 & 0.004 \\
-1.665 & -3.497 & 32.878\end{array}\right] \\
\rho=2 \varepsilon=1250 \alpha=0.98\end{array}$ & $\begin{array}{l}K=\left[\begin{array}{ccc}25.530 & -2.595 & -8.371 \\
0.097 & 21.744 & -17.936 \\
-5.620 & -2.438 & 12.232\end{array}\right] \\
\rho=2 \varepsilon=8669 \alpha=0.95\end{array}$ & $\begin{aligned} K & =\left[\begin{array}{ccc}25.849 & -4.399 & 1.839 \\
-9.249 & 21.571 & -5.454 \\
-6.849 & -5.581 & 14.655\end{array}\right. \\
\rho & =13.8 \varepsilon=4914 \alpha=0.96\end{aligned}$ \\
\hline
\end{tabular}

Table 3. Parameters for MPID controllers for different Methods (Case 1)

\begin{tabular}{|c|c|c||}
\hline & Constant & Dry \\
\hline M2 & $K_{c}=\left[\begin{array}{cc}181.673 & 29.368 \\
1.627 & 0.511\end{array}\right]$ & $K_{c}=\left[\begin{array}{cc}283.386 & -494.794 \\
0.058 & 0.635\end{array}\right]$ \\
& $K_{i}=\left[\begin{array}{cc}3427 & -5302 \\
3.5 & 36.9\end{array}\right]$ & $K_{i}=\left[\begin{array}{cc}5642.8 & 6996 \\
2.2 & 7.5\end{array}\right]$ \\
\hline M3 & $\rho=63.266 \varepsilon=170.561$ & $\rho=31.038 \varepsilon=117.231$ \\
\hline M4 & $K=\left[\begin{array}{cc}0.002 & 0.013 \\
-0.0 & 0.008\end{array}\right]$ & $K=\left[\begin{array}{cc}0.001 & -0.03 \\
0.0 & 0.025\end{array}\right]$ \\
\hline & $\quad K=\left[\begin{array}{cc}1694.5 & -564.1 \\
11.3 & 8.7\end{array}\right]$ & $\rho=4000 \varepsilon=1326700 \omega=0.002$ \\
\hline
\end{tabular}

Table 4. Parameters for MPID controllers for different Methods (Case 2) 
Therefore, the controller parameters $\varphi$ are optimal in the sense of minimising the cost function $J$ for specific $Q$ and $R$. For each method, the above problem was solved using the Matlab numerical optimisation function. This approach is justified when the process interaction is strong and the trial-and-error tuning approach would be time consuming. The optimal tuning matrices for all MPID controllers for Cases of 1 and 2 at various operating points are evaluated. The input and output weights in the cost function may be tuned in such a way that satisfactory closed loop performance, as well as effluent quality performance e.g. nitrogen removal improvement could be achieved.

\subsection{Evaluation criteria}

The MPID control strategies are tested using the nonlinear ASM1 model and the controller performance is evaluated using an index of the Aeration Energy (AE) as described in (Copp, 2002):

$$
A E=\frac{24}{T} \int_{t=7 d}^{t=14 d} \sum_{i=1}^{5}\left[0.4032 K_{L a i}(t)^{2}+7.8408 K_{L a i}(t)\right] d t
$$

where $K_{L a i}$ is the oxygen transfer coefficient $\left(\mathrm{d}^{-1}\right)$ in each reactor. $\mathrm{d}$ is the unit of time (a day). The average $\mathrm{AE}(\mathrm{kWh} / \mathrm{d})$ is calculated for the last 7 days of the dynamic data $(\mathrm{T})$.

\section{Simulation Results}

The MPID controller was evaluated in a simulation study where the full ASM1 was used to model the process. The nonlinear ASM1 was used for simulating the process. The constant influent flow has been utilised first to assess the controllers' ability to respond to set point changes, whilst the varying influent flow (dry and rain weather conditions) are used to provide a statistical evaluation of the controllers' performance with respect to disturbance rejection. Note that the time constants for DO and SNO are of the order of minutes (DO) and hours (SNO), respectively. The aim of the controller in Case 1 is to maintain the DO levels in the last three aerobic tanks at $\mathrm{DO}_{3}=1.5 \mathrm{mg} / 1, \mathrm{DO}_{4}=3 \mathrm{mg} / 1$ and $\mathrm{DO}_{5}=2 \mathrm{mg} / 1$. In Case 2, the set points for DO and the nitrate were set at $2 \mathrm{mg} / 1$ and $1 \mathrm{mg} / 1$, respectively. Notice that, for simplification, each method of tuning is denoted as M1, M2, M3 and M4 methods for Davison, Penttinen-Koivo, Maciejowski and proposed new method, respectively. For the first operating condition (constant influent flow), for both cases of 1 and 2, M4 clearly gives a promising result for compensating the changes in setpoints and better performance for disturbance rejection. This can be first revealed from Table 5 that summarise the results obtained for each control strategy for Case 1. The simulation result for Case 2 is plotted in Fig. 5(a-b).

The result demonstrates that M4 gives a better performance compared to the others for both setpoint tracking and disturbance rejection. M4 exhibits somewhat faster responses than the other controllers. The overshoots to setpoint changes are small and the settling time is about 10-15 minutes as shown in Table 5. The closed loop response for a setpoint change in M2 is satisfactory. The average settling time for DOs given by all control strategies is about 20 minutes which seems reasonable, except for DO5 given by M1 which takes much longer to settle. M3 needs to be fairly tuned in order to obtain a good tracking and disturbance rejection performance. M2 tends to make the system unstable as the controller gain is 
increased. M3 has better performance than M1 or M2, but it has slightly bigger overshoot than M4. Although the performance of M3 is satisfactory in some outputs, it uses the more time-consuming "sequential" identification procedure for obtaining the tuning constant. The performance of M1 is worst with the slowest response and large overshoot, as seen in Table 5. This method is not applicable in Case 2.

\begin{tabular}{||c|c|c|c||}
\hline & OS(\%) & $\mathbf{T}_{\mathbf{s}}$ (min) & SSQ \\
\hline $\mathrm{DO}_{\mathrm{M} 1}$ & 6.7 & 28 & $4.18 \mathrm{e}-5$ \\
\hline $\mathrm{DO}_{\mathrm{M} 1}$ & 8.3 & 43.2 & $3.08 \mathrm{e}-4$ \\
\hline $\mathrm{DO}_{\mathrm{M} 1}$ & 25 & 57.6 & $9.8 \mathrm{e}-4$ \\
\hline $\mathrm{DO}_{\mathrm{M} 2}$ & 0.7 & 7.2 & $3.28 \mathrm{e}-5$ \\
\hline $\mathrm{DO}_{\mathrm{M} 2}$ & 2 & 8.64 & $2.19 \mathrm{e}-4$ \\
\hline $\mathrm{DO}_{\mathrm{M} 2}$ & 15 & 5.76 & $9.76 \mathrm{e}-4$ \\
\hline $\mathrm{DO}_{\mathrm{M} 3}$ & 0.2 & 8.64 & $3.28 \mathrm{e}-5$ \\
\hline $\mathrm{DO}_{\mathrm{M} 3}$ & 1.8 & 8.65 & $1.65 \mathrm{e}-4$ \\
\hline $\mathrm{DO}_{\mathrm{M} 3}$ & 10 & 8.64 & $9.59 \mathrm{e}-4$ \\
\hline $\mathrm{DO}_{3}$ & 0.3 & 2.85 & $9.97 \mathrm{e}-6$ \\
\hline $\mathrm{DO}_{\mathrm{M}}$ & 2 & 2.88 & $7.10 \mathrm{e}-5$ \\
\hline $\mathrm{DO}_{\mathrm{M}}$ & 2 & 2.80 & $4.26 \mathrm{e}-4$ \\
\hline
\end{tabular}

Table 5. Dynamic performance comparison of MPID controllers (Case 1)- (OS: Overshoot, $\mathrm{T}_{\mathrm{s}}$ : Settling time, SSQ: the residual sum of squares)

(a)
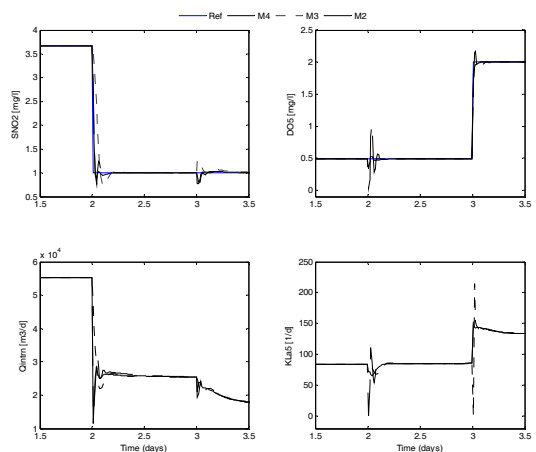

(b)
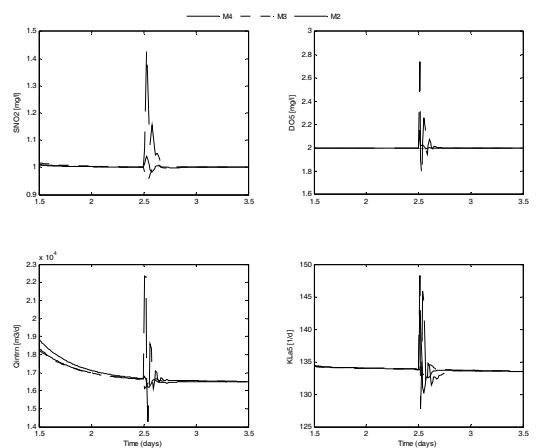

Fig. 5. Dynamic performance comparison of MPID controllers (Case 2)- a) set point tracking; b) disturbance rejection

It is also of great interest to study how the controllers perform under different operating conditions (dynamic influent flows). The statistical evaluation of the performance for Case 1 for each control strategy under dry and rain condition is depicted in Fig. 6, whilst Fig. 7 reveals the performance (Case 2) of disturbance rejection under dry condition. 
a)

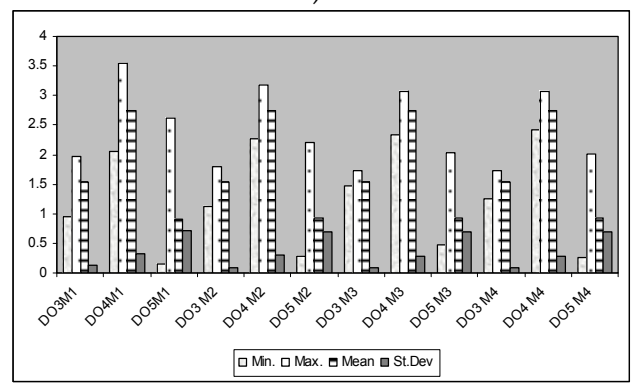

(b)

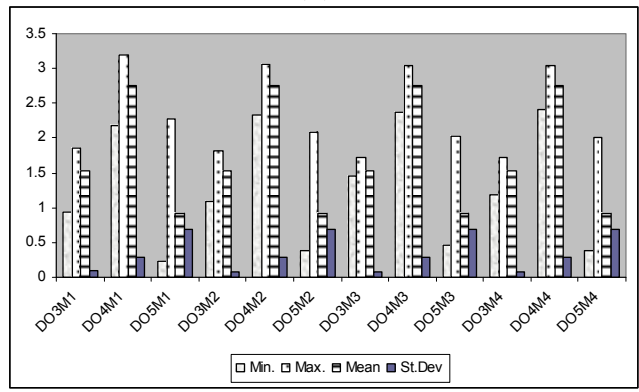

Fig. 6. Dynamic influent statistics (Case 1)- a) Dry weather; b) Rain weather
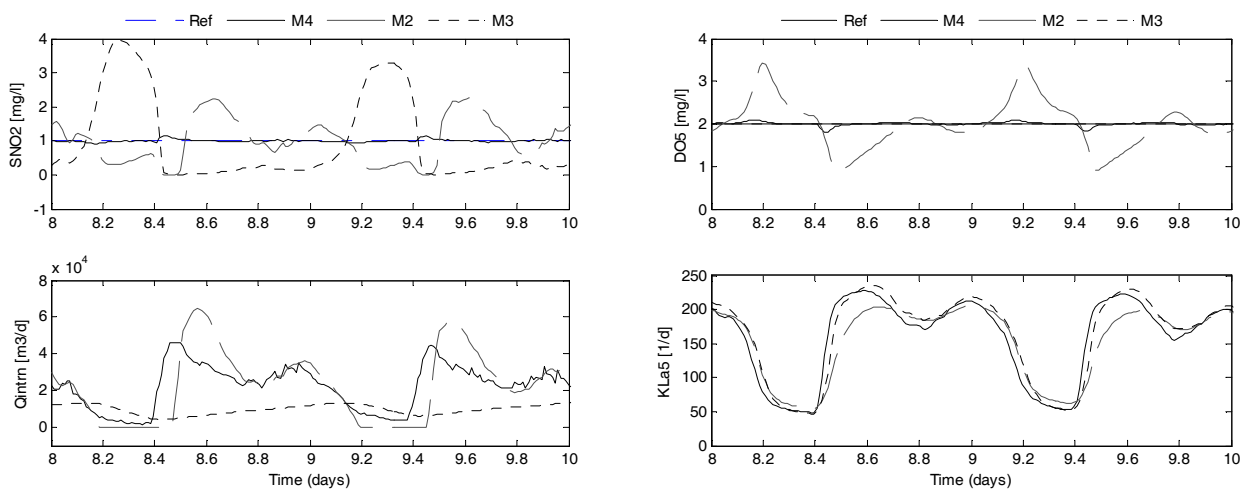

Fig. 7. Disturbance rejection under dry influent flow (Case 2)

Due to high nonlinearities in Case 2, only dry influent flow has been investigated and an adaptive controller is required to design the controller for rain condition. In all cases the result from the statistical evaluation of the performance (Fig. 6) shows lower output error for M4. The result of simulation from the $8^{\text {th }}$ to the $10^{\text {th }}$ day of influent data is shown in Fig. 7. These results will also confirm that M4 has the best performance. M3 shows good tracking properties and compensates the disturbances for $\mathrm{DO}_{5}$, but it has no control on $\mathrm{S}_{\mathrm{NO} 2}$ as it is evident from the low value of $\mathrm{Q}_{\text {intrn. }}$ M4 is also more flexible and the tuning parameter, $\mathrm{a}$ makes the plant frequency analysis easier to handle. In addition, M2 performs better than M3, but not as good as the M4.

\subsection{Robustness performance analysis}

The control design strategy is also analysed in term of robustness performance requirement and in this case, constant influent condition is applied. Fig. 8 shows the open loop singular values for Cases 1 and 2 
a)

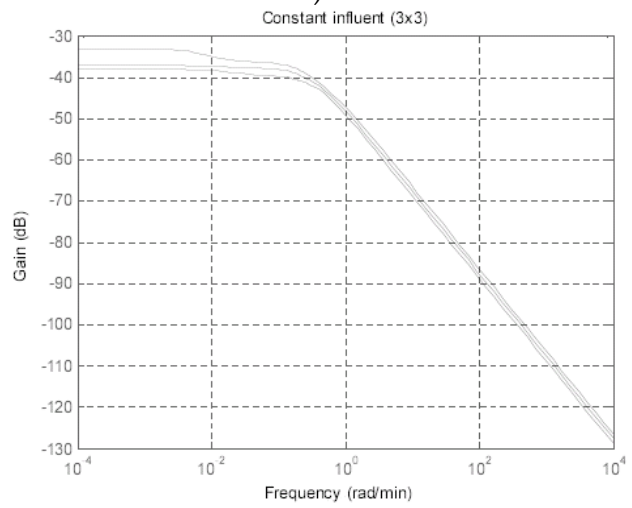

(b)

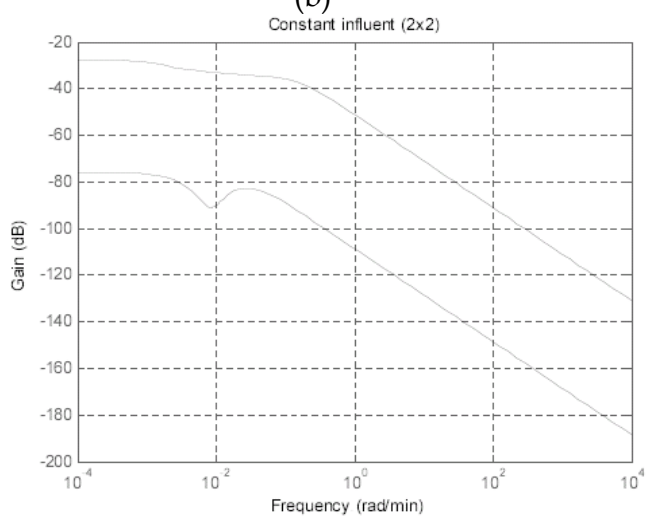

Fig. 8. Open loop singular values - a) Case 1 ; b) Case 2

The singular values are relatively small at low frequencies in both cases indicating that controlling the variables of interest are not an easy task. Moreover, there is a significant difference in magnitude in each loop for design case 2 indicating that controlling the variables are therefore more difficult. The ability of multivariable PID controller to deal with this difficulty is especially of importance since its closed loop performance is dictacted by low frequency gains of the variable of interest. The open loop bandwidth of $0.02 \mathrm{rad} / \mathrm{min}$ is given by Case 1 whilst Case 2 shows a significant difference of bandwidth frequency in each control loop.

Fig. 9 compares the results of sensitivity, $(\mathrm{I}+\mathrm{GK})^{-1}$ and complementary sensitivity, GK (I + $\mathrm{GK})^{-1}$ plots of different control strategies in Case 1. It can be seen that the magnitudes of sensitivity for the three variables (DOs) at low frequency are higher for M1 compared to other control strategies. This implies that performance of M1 in rejecting disturbance is worst. The magnitude of $(\mathrm{I}+\mathrm{GK})^{-1}$ for M2 is lowest followed by M4 and M3. This means that M2 is less susceptible to disturbances. Note that although the closed loop sensitivity resulting from M2 is superior to that with the other three control strategies (M1, M3 and M4), the worst-case gain behaviour is much worse as can be seen in Fig. 9. This is also leads to a lower stability margin provided by M2 controller design. For robustness, we also need to keep GK $(\mathrm{I}+\mathrm{GK})^{-1}$ small. Although M1 gives the best result in terms of noise immunity, it is however the lowest performance in terms of closed loop bandwidth and in rejecting disturbance. The methods of M3 and M4 give satisfactory results, being particularly effective for a given frequency range. However, M4 gives slightly better results compared to M3 especially the closed loop bandwidth and disturbance rejection. Considering the overall performance characteristics given by all different control strategies, the method M4 is the most reliable. 
(a)

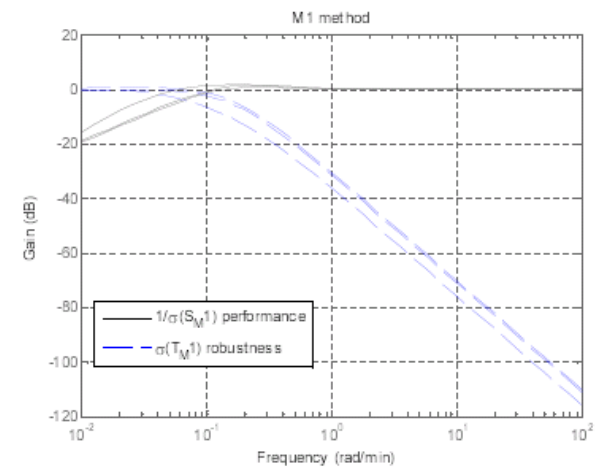

(b)

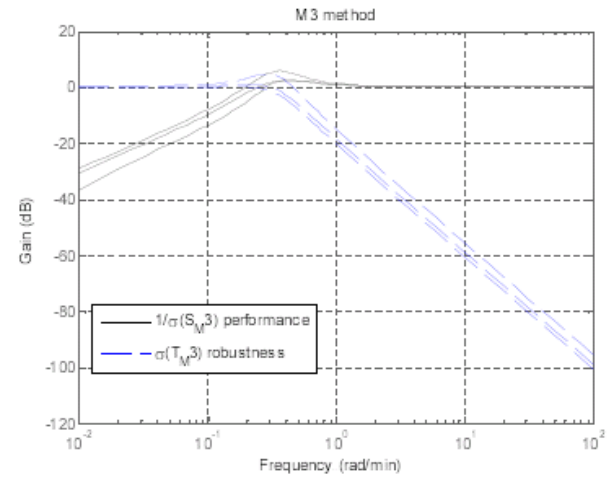

(b)

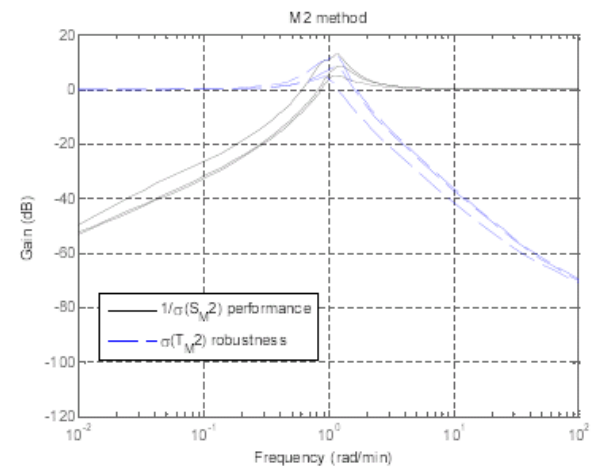

(d)

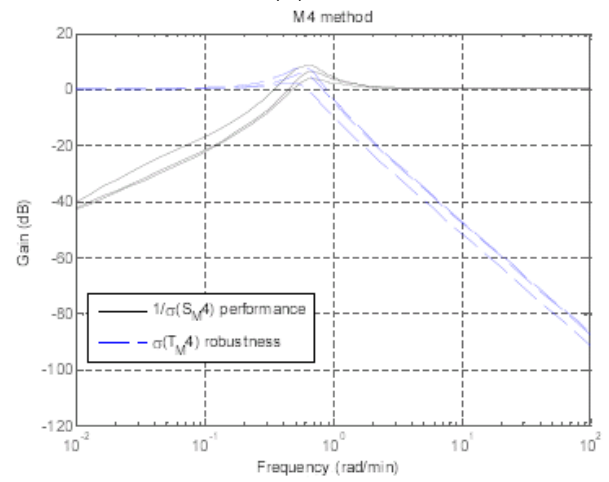

Fig. 9. Performance robustness analysis of Case 1 - sensitivity- a) Davison method; b) Penttinen method; c) Maciejowski method; d) Proposed new method

Fig. 10 compares the results of sensitivity, $(\mathrm{I}+\mathrm{GK})^{-1}$ and complementary sensitivity, GK (I + $\mathrm{GK})^{-1}$ plots of different control strategies in Case 2. Method M1 is not applicable, therefore it is not applied in this case. In this case, we have two different frequency bandwidth in the control loops. This leads to challenges in control tuning to obtain simulataneously a good performance in both of loops. It can be seen that the measurement noise is being amplified over a smaller range of frequencies in method M2. However, M2 considers the worst performance in term of disturbance rejection, i.e. highest magnitude of $(I+G K)^{-1}$ at low frequency. As previously discussed in Case 1, M3 and M4 also give better performance in disturbance rejection in Case 2. Fig. 10 shows that, although M3 gives the best result in rejecting disturbance of loop 2 (DO5), i.e. lowest magnitude of $(I+G K)^{-1}$ at low frequency, it is however the worst in noise suppression, i.e. highest magnitude of GK (I + GK) ${ }^{-1}$ for loop 1 (SNO;2) at high frequency. Moreover, M3 has lower stability margin compared to M4 and M2. Overall, M4 provides satisfactory results in the simultaneous multiloop control tuning. It shows good performance in both loops in terms of closed loop bandwidth and can suppress noise better. 
(a)

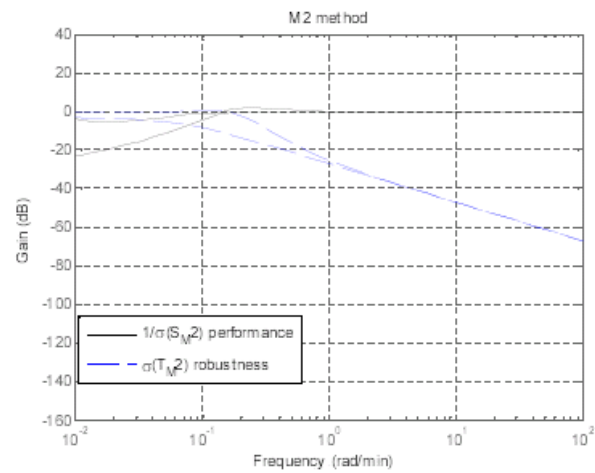

(b)

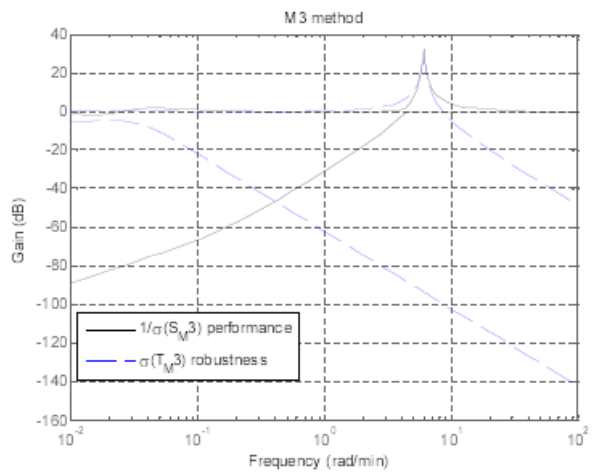

(c)

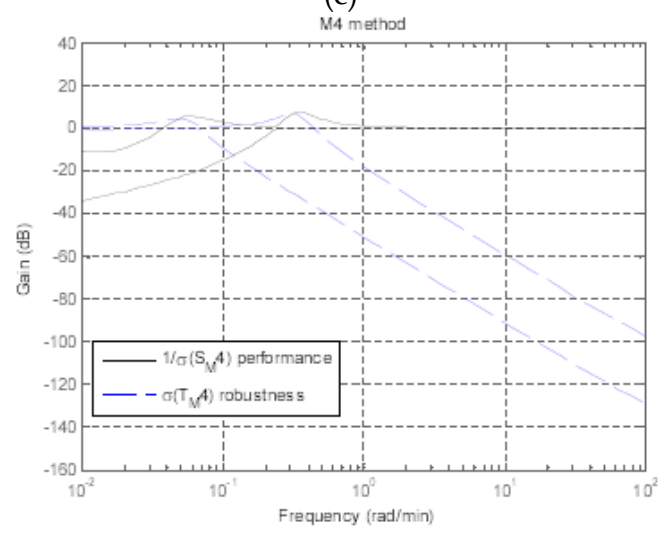

Fig. 10. Performance robustness analysis of Case 2 - sensitivity- a) Penttinen method; b) Maciejowski method; c) Proposed new method

Fig. 11 shows the plots of input disturbance, $\bar{\sigma}(I+G K)^{-1} G$ for both cases of 1 and 2 . In this case, the variables of control should prevail in zero steady state errors subject to input disturbances and/or changes in setpoint, i.e. changes in the oxygen transfer coefficients or internal recirculation flow. This can be clearly observed from the positive gradients at low frequency regions of the plots given by all control strategies. It can also be seen from Fig. 11 that the magnitude of $\bar{\sigma}(I+G K)^{-1} G$ is relatively higher for M2 (50-55 dB at 10-2 rad/min) compared with M4 (40-45 dB at 10-2 $\mathrm{rad} / \mathrm{min}), \mathrm{M} 3$ (30-35 dB at 10-2 $\mathrm{rad} / \mathrm{min} \mathrm{rad} / \mathrm{min})$ and M1 (15-20 dB at 10-2 $\mathrm{rad} / \mathrm{min} \mathrm{rad} / \mathrm{min})$. Though M2 shows a good performance to input disturbance in Case 1, it appears to be the worst performance due to input disturbance in Case 2. Since the performance measure given by M4 is satisfactory in both cases, the method is proven to be useful for different frequency bandwidth. 
(a)

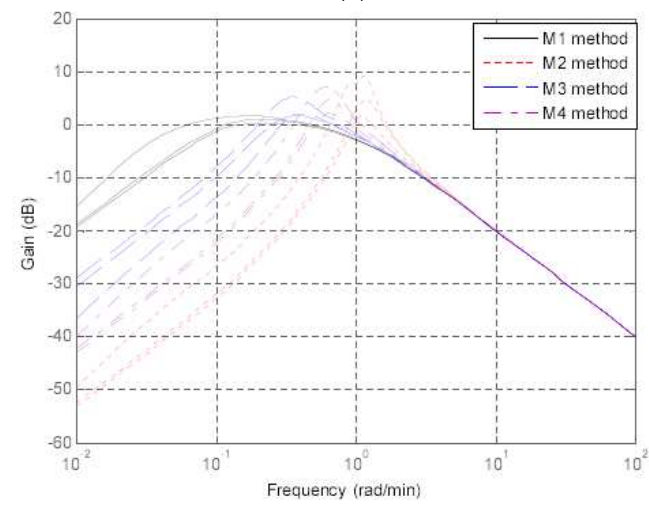

Fig. 11. Performance robustness analysis - input disturbance- (b)

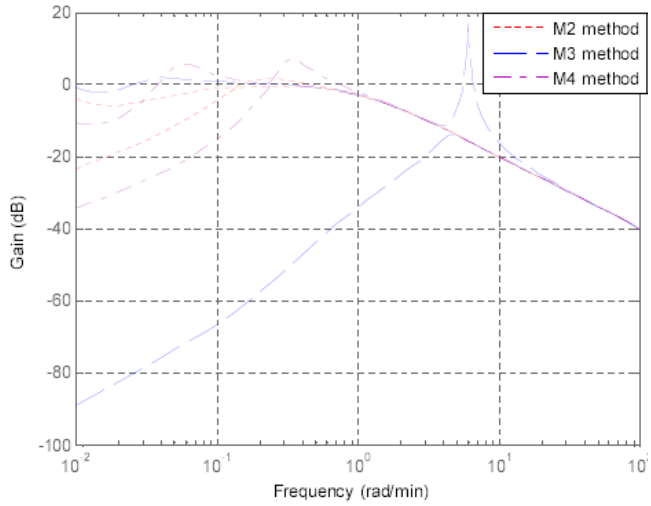

a) Case 1; b) Case 2

\subsection{Performance evaluation}

Here, the performance of the plant is presented for Cases 1 and 2. In Case 1, the effect of controlling three dissolved oxygen in the last three aerated tanks is shown in Fig. 12. As seen in Fig. 12, the DO in reactor 1 and reactor 2 are not controlled. Clearly, the same output of DO, both in the effluent and under flow are demonstrated, as the ones given by the DO in the last aerated tank (reactor), both for dry and rain flow conditions. Control strategies were also evaluated against the criteria described in (35) for Case 2 as shown in Table 6.

\begin{tabular}{|c|c|c|c|}
\hline & $\begin{array}{c}\text { Aeration energy } \\
\mathbf{( k W h / d )}\end{array}$ & $\begin{array}{c}\text { Average } \mathbf{N H}_{4^{-}} \\
\mathbf{N}_{\text {eff }}(\mathbf{m g} / \mathbf{l})\end{array}$ & $\begin{array}{c}\text { Average } \mathbf{N O}_{3^{-}} \\
\mathbf{N}_{\text {eff }}(\mathbf{m g} / \mathbf{l})\end{array}$ \\
\hline Benchmark & 7241.27 & 2.528 & 12.439 \\
\hline M2 & $6532.14(-9.8 \%)$ & $3.029(+19.8 \%)$ & $12.489(+0.4 \%)$ \\
\hline M3 & $6387.12(-11.7 \%)$ & $2.267(-10.3 \%)$ & $14.53(+16.8 \%)$ \\
\hline M4 & $6376.11(-11.9 \%)$ & $2.411(-4.6 \%)$ & $12.045(-3.2 \%)$ \\
\hline
\end{tabular}

Table 6. Evaluation criteria for different control tuning strategies for dry influent case.

The basic control strategy in benchmark simulation study, proposed by (Copp, 2002) is used as a reference case for comparison. The evaluation criteria considered are aeration energy, effluent ammonia nitrogen and effluent nitrate nitrogen. The MPID control strategies were evaluated for DO-Nitrate dry weather model against single loop PI controllers used in the COST benchmark. A lower aeration cost (AE) is achieved with MPID. These are about 9.8\%, $11.7 \%$ and $11.9 \%$, for M2, M3 and M4, respectively. The average effluent ammonia $\left(\mathrm{NH}_{4}{ }^{-}\right.$ $\mathrm{N}_{\text {eff }}$ ) was reduced by $10.3 \%$ and $4.6 \%$, for M3 and M4, respectively. M2 gave slightly higher average effluent ammonia but still below the discharge limit $(4 \mathrm{mg} / \mathrm{l})$. Better total nitrogen removal is achieved using M4 for both ammonia and nitrate in the effluent. 
(a)
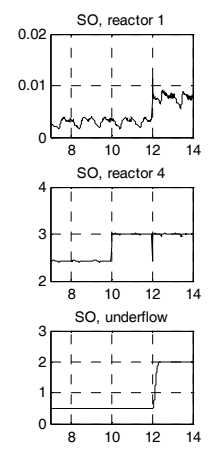
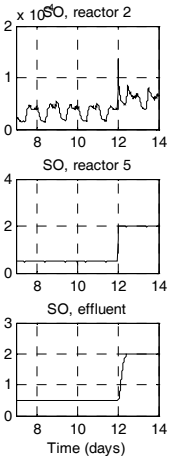
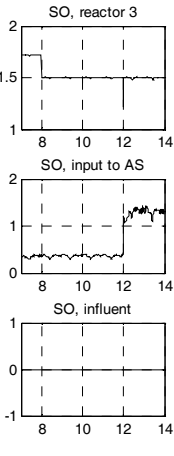

(b)
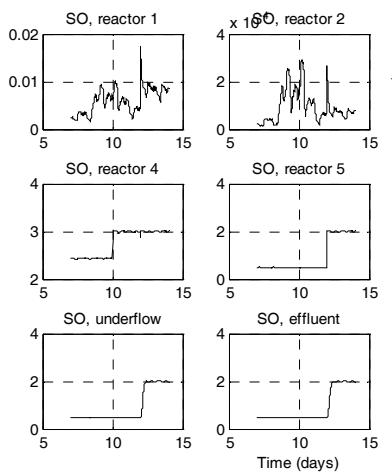
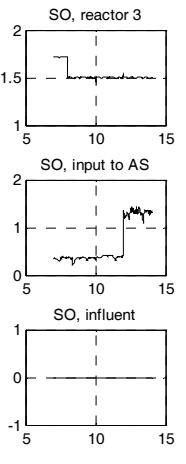

Fig. 12. Plant performance of DO for Case 1, (a) dry influent condition; (b) rain influent condition

\section{Conclusion}

The objective of the study was to use MPID controllers to improve closed loop performance and reduce loop interactions. Three tuning strategies were compared and a new one was introduced. All methods require information only from simple step or frequency tests. The methods are based on decoupling the system at different frequency points. To identify the most effective control strategy, RGA analysis were performed. It was proposed to use DRGA to find the best frequency point for decoupling. A procedure was also developed to fine-tune the controllers using an optimisation procedure. Extensive simulation studies on a nonlinear ASM1 model demonstrated that the proposed method performed significantly better in setpoint tracking properties and disturbance rejection and gave the best performance with respect to decoupling capabilities. The results suggest considerable improvement can be achieved in terms of energy savings and nitrogen removal with a properly tuned MPID controller. The methods demonstrate that the controller tuning influences multiloop system performance.

\section{References}

El-Din, A. G. Smith \& D. W. (2002). A combined transfer function noise model to predict the dynamic behaviour of a full scale primary sedimentation tank model. Water Research, Vol 36, pages 3747-3764.

Cote, P. L., G. A. Ekama \& G.v.R. Marais (1995). Dynamic modelling of the activated sludge process: improving prediction using neural networks. Water Research, Vol 29, pages 995-1004.

Robertson, G. A. \& T. Cameron (1996). Analysis of dynamic process models for structural insight and model reduction -part 1. structural identification measures. Computer and Chemical Engineering, Vol 21, No.5, pages 455-473.

M. Henze, C.P.L.Grady Jr., W.Gujer, G.v.R.Marais \& T.Matsuo (1987). Activated sludge model no.1. IAWQ. Scientific and Technical Report no.1, IAWQ, London. 
Chotkowski, W., Brdys, M. A. \& Konarczak, K. (2005). Dissolved oxygen control for activated sludge processes, International Journal of System Science, Vol 12, pages 727736.

Y. Ma, Y. Peng \& S. Wang, (2005). Feedforward - feedback control of dissolved oxygen concentration in a predenitrification system, Bioprocess. Biosyst. Eng. Vol 27, pages 223-228.

Piotrowski, R. \& Brdys M. A. (2005) Lower-level controller for hierarchical control of dissolved oxygen concentration in activated sludge processes, In Proceeding of the $16^{\text {th }}$ IFAC world congress, Prague, pages 4-8.

A. Stare, D. Vrečko, N. Hvala \& S. Strmčnik. (2007) Comparison of control strategies for nitrogen removal in an activated sludge process in terms of operating costs: A simulation study, Water Res. Vol 41, pages 2004-2014.

E. Mats, B. Berndt \& A. Mikael. (2006). Control of the aeration volume in an activated sludge process using supervisory control strategies, Water Res. Vol 40, pages 1668-1676.

I. Takács, G.G.Patry \& D.Nolasco. (1991). A dynamic model of the clarification thickening process. Water Res. Vol 25, pages 1263-1271.

J.B. Copp. (2002). COST Action 624, The COST simulation benchmark-Description and simulator manual, European Communities, Luxembourgh.

De Moor, B. (1988). Mathematical concepts and technique for modelling of static and dynamic systems. PhD thesis. Dept. of Electrical Engineering, Katholieke Universiteit Leuven, Belgium.

Moonen, M., B. De Moor, L. Vandenberghe \& J. Vandewalle (1989). On and offline identification of linear state space models. Internal Journal Control, Vol 49, No. 1, pages 219-232.

Verhaegen, M. (1994). Identification of the deterministic part of mimo state space models given in innovation form from input-output data. Automatica, Vol 30, No. 1, pages 61-74.

Söderström, T. and P. Stoica (1989). System Identification. Prentice Hall, Inc., Englewood Cliffs, New Jersey, USA.

Bristol, E.H. (1996). On a new measure of interaction for multivariable process control. IEEE Trans. On Auto Control, Vol 11, pages 133-134.

Kinnaert, M. (1995). Interaction measures and pairing of controlled and manipulated variables for multiple-input multiple-output systems: A survey. Journal A, Vol 36, No.4, pages 15-23.

Davison, E. (1976). Multivariable tuning regulator. IEEE Transaction on Automatic Control, Vol 21, pages 35-47.

Penttinen, J. \& Koivo, N.H. (1980). Multivariable tuning regulators for unknown systems, Automatica, Vol 16, pages 393-398.

Maciejowski, J. M. (1989). Multivariable feedback design, Addison Wesley, Wokingham, England. 
www.intechopen.com 


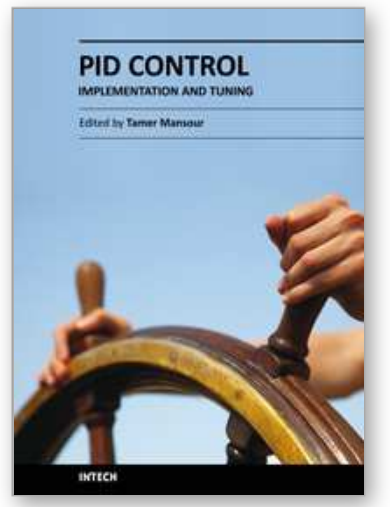

\author{
PID Control, Implementation and Tuning \\ Edited by Dr. Tamer Mansour
}

ISBN 978-953-307-166-4

Hard cover, 238 pages

Publisher InTech

Published online 19, April, 2011

Published in print edition April, 2011

The PID controller is considered the most widely used controller. It has numerous applications varying from industrial to home appliances. This book is an outcome of contributions and inspirations from many researchers in the field of PID control. The book consists of two parts; the first is related to the implementation of PID control in various applications whilst the second part concentrates on the tuning of PID control to get best performance. We hope that this book can be a valuable aid for new research in the field of PID control in addition to stimulating the research in the area of PID control toward better utilization in our life.

\title{
How to reference
}

In order to correctly reference this scholarly work, feel free to copy and paste the following:

Norhaliza Abdul Wahab, Reza Katebi and Jonas Balderud (2011). Multivariable PID control of an Activated Sludge Wastewater Treatment Process, PID Control, Implementation and Tuning, Dr. Tamer Mansour (Ed.), ISBN: 978-953-307-166-4, InTech, Available from: http://www.intechopen.com/books/pid-controlimplementation-and-tuning/multivariable-pid-control-of-an-activated-sludge-wastewater-treatment-process

\section{INTECH}

open science | open minds

\section{InTech Europe}

University Campus STeP Ri

Slavka Krautzeka 83/A

51000 Rijeka, Croatia

Phone: +385 (51) 770447

Fax: +385 (51) 686166

www.intechopen.com

\section{InTech China}

Unit 405, Office Block, Hotel Equatorial Shanghai

No.65, Yan An Road (West), Shanghai, 200040, China

中国上海市延安西路65号上海国际贵都大饭店办公楼 405 单元

Phone: +86-21-62489820

Fax: +86-21-62489821 
(C) 2011 The Author(s). Licensee IntechOpen. This chapter is distributed under the terms of the Creative Commons Attribution-NonCommercialShareAlike-3.0 License, which permits use, distribution and reproduction for non-commercial purposes, provided the original is properly cited and derivative works building on this content are distributed under the same license. 